This item was submitted to Loughborough's Research Repository by the author.

Items in Figshare are protected by copyright, with all rights reserved, unless otherwise indicated.

\title{
The policy choices and reaction functions of Bank of England MPC Members
}

\section{PLEASE CITE THE PUBLISHED VERSION}

http://dx.doi.org/10.4284/sej.2009.76.2.482

\section{PUBLISHER}

(C) University of North Carolina

\section{VERSION}

NA (Not Applicable or Unknown)

\section{PUBLISHER STATEMENT}

This work is made available according to the conditions of the Creative Commons Attribution-NonCommercialNoDerivatives 4.0 International (CC BY-NC-ND 4.0) licence. Full details of this licence are available at: https://creativecommons.org/licenses/by-nc-nd/4.0/

\section{LICENCE}

CC BY-NC-ND 4.0

\section{REPOSITORY RECORD}

Harris, Mark N., and Christopher Spencer. 2019. "The Policy Choices and Reaction Functions of Bank of England MPC Members". figshare. https://hdl.handle.net/2134/15968. 


\title{
The Policy Choices and Reaction Functions of Bank of England MPC Members
}

\author{
Mark N. Harris* and Christopher Spencer†t
}

\begin{abstract}
The results of an econometric exercise are presented, showing that Monetary Policy Committee (MPC) members appointed from outside the ranks of Bank of England staff (outsiders) react differently to forecasts of inflation and output than those appointed from within the Bank (insiders). All results are reinforced by the well-established findings that, compared with outsiders, insiders choose higher interest rates, are more likely to vote as a bloc, and feature on the winning side of policy decisions more frequently. On the basis of these results, it is argued that the current MPC framework is biased toward the policy choices of insiders.
\end{abstract}

JEL Classification: E50, E60

\section{Introduction}

In May 1997 decisions on UK monetary policy were delegated to a Monetary Policy Committee (MPC), and in a move toward transparency, a decision to publish the voting record shortly after each meeting was taken. Releasing such information into the public domain has focused parliamentary, financial, and news media interest on the voting behavior of individual MPC members, who are mandated with hitting a government-set inflation target. Split decisions constitute stories in themselves, ${ }^{1}$ and it is commonplace to draw attention to differences in votes cast by members appointed from within and outside the ranks of Bank of England staff (hereafter referred to as "insiders" and "outsiders," respectively).

In this paper, it is demonstrated that a member's type-which here refers to the insideroutsider distinction - has a substantial bearing on the policy choices of MPC members. As in previous work (Gerlach-Kristen 2003), insiders can (still) be construed as behaving more "conservatively" than outsiders, choosing higher interest rates. Furthermore, the extent to

\footnotetext{
* Department of Econometrics and Business Statistics, Monash University, Clayton, Victoria 3800, Australia; E-mail mark.harris@buseco.monash.edu.au.

† Department of Economics, Loughborough University, Leicestershire LE11 3TU, UK; E-mail c.g.spencer@ lboro.ac.uk.

† Department of Economics, Loughborough University, Leicestershire LE11 3TU, UK; E-mail c.g.spencer@ lboro.ac.uk.

Financial support from the Economic and Social Research Council (ESRC) is gratefully acknowledged (ESRC Postgraduate Studentship R42200134224). This paper has benefited from the comments of Ali Choudhary, Petra Gerlach-Kristen, Charles Goodhart, and two anonymous referees. Spencer would like to extend special thanks to Paul Levine for advice and encouragement during the writing of this paper. The usual disclaimer applies.

Received April 2008; accepted January 2009.

${ }^{1}$ For example, the Financial Times on May 22, 2003, reported a 5-4 split amongst MPC members in the policy meeting held earlier that month - thereby highlighting the fact that when monetary policy is delegated to a committee, its members can be sharply divided over the appropriate policy stance. Also see the April 16, 1998, editions of the Financial Times (p. 1) and The Times 2 (p. 25), which ran stories on the Governor's use of the casting vote in the March meeting for a second consecutive month.
} 
which each group engages in bloc voting is evidenced, confirming the suggestion that whereas insiders vote as a "cohesive homogeneous group" (Edmonds 1999) outsiders are less inclined to do so. ${ }^{2}$ Descriptive statistics show that insiders are also more likely to find themselves on the winning side of a policy decision and are less likely to vote to change the interest rate. These simple results reinforce the outcome of an econometric exercise suggesting that insiders and outsiders have different reaction functions: Although the inflation forecast (expressed as a deviation from target inflation) is a highly significant factor in driving votes to change the interest rate across both groups, insiders and outsiders differ in their responses to these deviations; furthermore, the role of real output growth forecasts (expressed in deviation form from assumed potential output growth) play, at best, a negligible role in determining insiders' and outsiders' voting decisions. Finally, the effect of past voting behavior and policy decisions on current behavior is more pronounced for outsiders, whereas the effect of different MPC chairmen is insignificant for both groups. Findings are based on voting data contained in the Minutes of Monthly Meetings from June 1997-May 2006, a period characterized by 109 meetings in which 955 votes were cast. It covers the first nine years of the MPC, encompassing the entire period for which the MPC was chaired by Eddie George, and the first three years of meetings under his successor, Mervyn King.

In light of the findings presented here, it is suggested that the MPC is characterized by a structure that leads to insiders dominating decisions. This is no moot point. Although the presence of outsiders is designed to ensure that "the MPC benefits from thinking and expertise in addition to that gained inside the Bank," ${ }^{33}$ such perceived benefits can in practice be limited if the structure of the MPC is such that a single group within the committee is able to systematically dominate interest rate decisions. Consequently, the benefits to UK monetary policy from delegating interest rate decisions to a committee are not being fully realized - that is, if one assumes the rationale for establishing a MPC is to engender policy decisions that reflect a heterogeneity of views.

\section{Rationalizing MPC Voting}

There are strong reasons to suppose that the voting behavior of insiders and outsiders will differ. First, as members of the same organization, insiders could have more of an incentive to agree with each other at MPC meetings: Voting against one's peers might be perceived as detrimental to future career advancement. ${ }^{4}$ For this reason, it might be predicted that insiders will vote together as a group. Outsiders might not face similar pressure given they emanate from a wide array of different organizations. Buiter (1999) also suggests insiders' votes might reflect an organizational consensus or "Bank" view. Second, members within each group may hold different beliefs about the macroeconomic effect of the timing of decisions, a view supported by the publication of the Minutes in the "Tactical considerations" and "Immediate policy decision" sections. On this view, insiders and outsiders might share the same policy

2 “. . . on the face of it most of the five internal members seem to vote together, almost as a bloc" (House of Lords 1999).

${ }^{3}$ http://www.bankofengland.co.uk/monetarypolicy/overview.htm.

${ }^{4}$ Members' votes are here described as policy choices as opposed to policy preferences. As one anonymous referee has pointed out, a member's vote might not reflect their true interest rate "preference": Some members could feel they have to "fall into line" with other MPC members (e.g., because of career concerns), thereby voting for a policy that would not otherwise have been chosen. 
objective (i.e., to hit a government inflation target) but try to achieve it in different ways. Third, different members may base their voting decisions on different information sets: For example, outsiders might attach less importance than insiders to forecasts generated by the Bank's suite of in-house forecasting models. There is evidence to corroborate this view: Sushil Wadhwani (2002) suggests that during his time as an MPC outsider, the Bank models incorporated "too pessimistic" a view about the level of potential output; Wallis (2002) suggests that the Bank's quarterly inflation projections systematically overpredicted future inflation, a fact that is also recognized in the Minutes for August 2000 (p. 9). If other outsiders held similar opinions and if one assumes that insiders were more wed to the Bank's in-house forecasts, it might be predicted that of the two groups, outsiders would ceteris paribus vote for lower interest rates.

Some of the arguments cited above have been used to account for findings in the literature that examine MPC voting behavior. ${ }^{5}$ Gerlach-Kristen (2003) shows that disagreements between members of the Bank's MPC are typically the rule and not the exception. Between June 1997 and April 2003, insiders dissented far less frequently than outsiders, and whereas insiders dissented overwhelmingly on the side of monetary tightness, outsiders did so on the side of monetary ease. According to one argument, outsiders might attempt to raise their public profile by dissenting, in that it attracts media attention. By contrast, insiders might not only dissent less because of an organizational consensus, as in Buiter (1999) - which could promote bloc voting and voting against the majority less frequently — but disagreeing with one's colleagues on the MPC might hamper career prospects at the Bank. This view can be traced back to, for example, Havrilesky and Schweitzer (1990), who propose that the presence of career concerns is an important factor determining the decision to dissent on the U.S. Federal Open Market Committee (FOMC). In this sense, the way a member "performs" on the MPC is not just measured as their ability to hit an inflation target, so to speak, but judged according to their propensity to agree with members of his or her type. Building on this work, Harris and Spencer (2008) investigate the effect of MPC members' career backgrounds and experiences on dissent voting. Econometric estimates suggest that career effects are negligible, with the largest determinant of a member's decision to dissent being their type. Another strand of MPC literature has exploited the heterogeneity in members' votes to predict future monetary policy decisions (Gerlach-Kristen 2004) and shed light on the factors underlying MPC decision making (Bhattacharjee and Holly 2004). In both contributions, information contained in the voting record increases the predictability of monetary policy decisions.

The MPC's reaction function has also been the subject of academic interest. Chevapatrakul, Mizen, and Kim (2003) argue that the MPC does not follow simple "Taylorstyle" rules when setting monetary policy; rather, it uses a broad set of information variables when making a decision. With the use of ordered probit analysis, Gascoigne and Turner (2004) find evidence that the MPC's reaction function is asymmetric. Besley, Meads, and Surico (2008) show that although MPC decisions are marked by voter heterogeneity, reactions to the inflation forecast and output gap are not significantly different on the basis of a member's type and career experience. Finally, Goodhart (2005) suggests that the inflation and real output growth forecasts published in the Bank's quarterly Inflation Report are not those of most

${ }^{5}$ This paper has parallels with the literature on U.S. Federal Open Market Committee (FOMC) voting behavior. In much the same way as insiders and outsiders are differentiated, FOMC studies distinguish Federal Reserve Board Members from Reserve Bank Presidents. Because MPC votes are modeled as a function of the economic environment, this paper is perhaps closest to Tootell (1991), who tests but fails to find evidence to support the hypothesis that Federal Reserve Bank Presidents vote more "conservatively" than Board Governors. Put another way, Board Governors and Bank Presidents share the same reaction functions. 
relevance in explaining the MPC's policy decisions, in that they are conditioned on the interest rate prevailing after the policy decision has been taken (i.e., they are ex post forecasts). To overcome this problem, Goodhart constructs a series of ex ante forecasts that are closer to the ones on which policy decisions are based. Reaction function estimates with the use of this data suggest that the MPC acted aggressively to deviations in inflation from target. Given Goodhart's experience as an MPC member, his argument has particular saliency. His approach is revisited in the construction of the variables used in estimation.

Finally, with respect to the UK monetary policy framework, the classification of monetary policy committee types by Blinder (2007) into autocratically collegial, genuinely collegial, and individualistic varieties has particular saliency. According to this typology, the Bank of England MPC emerges as being individualistic, attributable to the fact that during the course of meetings, unanimity is neither necessarily expected nor sought, and members "not only express their own opinions verbally, but probably also act on them by voting" (Blinder 2007, p. 119). The influence of the chairman is thus identified as being less pronounced than for collegial committees (such as the FOMC and the European Central Bank Governing Council), wherein the role of the chairman in shaping decisions is deemed much greater. With respect to the typology of committees outlined above, Gerlach-Kristen (2008) is notable for extending the work of Blinder (2007) to a more formal setting, with emphasis on the role of the chairman.

\section{MPC Framework and Policy Performance}

The MPC is structured as follows: Five members are chosen from within the ranks of Bank staff, hence the name insiders. Three of these members serve five-year terms, namely the Governor of the Bank and two Deputy Governors. The remaining two insiders are chosen by the Governor and serve three-year terms. These individuals have traditionally been the Chief Economist and the person responsible for monetary operations. Therefore, when the Governor appoints Bank staff to these positions, he is effectively choosing who he wants to sit on the MPC. ${ }^{6}$ The remaining four members are chosen from outside the ranks of Bank staff-hence the name outsiders - and are appointed directly by the Chancellor of the Exchequer. In this sense, outsiders cannot be viewed as Bank "representatives," typically being chosen from the private sector and academia. Outsiders serve three-year terms. All members' terms are renewable. Monetary policy is determined monthly by simple majority rule after a vote on the interest rate tabled by the Governor, who chairs the MPC. In the event of a split decision, the Governor has a casting vote.

In terms of inflationary performance, the MPC met its objectives during its first nine years. The general trend was for the interest rate to fall, and inflation as measured by the both the Retail Price Index excluding mortgage interest repayments (RPIX) and the Consumer Price Index (CPI) remained low and stable. Indeed, both RPIX and CPI inflation remained close to their respective target rates of 2.5\% and 2\% (the 2.5\% year-on-year increase in RPIX inflation was the adopted target between June 1997 and December 2003. Thereafter, the MPC was required to hit $2 \%$ year-on-year CPI inflation). On no occasion did the inflation rate deviate by more than one percentage point either side of its target rate, which would have required the Governor to write an open letter to the Chancellor expounding both the causes and expected

\footnotetext{
${ }^{6}$ The authors thank Charles Goodhart for clarifying these points.
} 


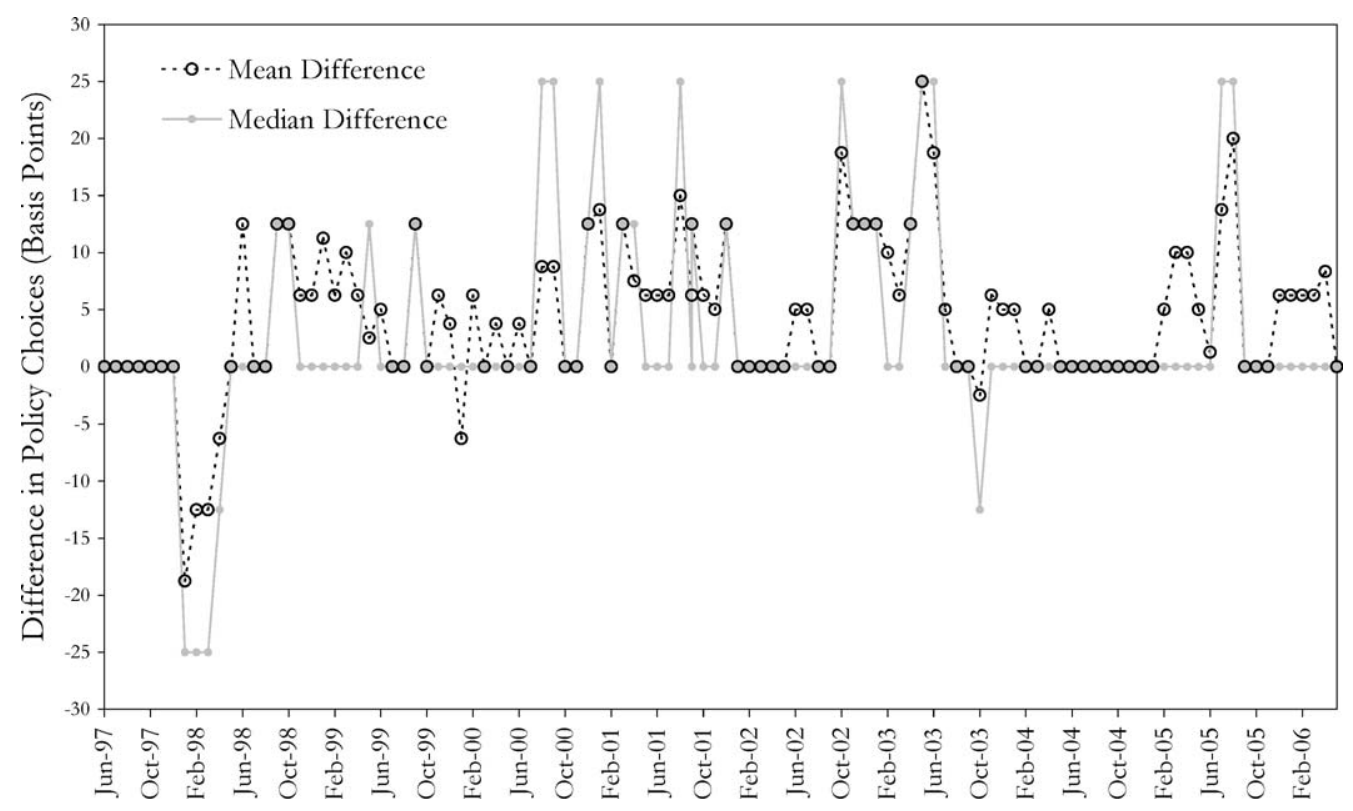

Figure 1. Differences in mean and median chosen group interest rates, Insiders versus Outsiders

duration of the deviation and the measures the MPC would adopt to bring inflation to target. The interest rate was raised, lowered, and left unchanged on 14, 17, and 78 occasions respectively, reflecting the inertial nature of monetary policy. When policy did change, it is hallmarked by what might be referred to as policy gradualism: Rates are changed upward or downward in a series of small steps rather than fewer relatively larger ones. Furthermore, the MPC is most likely to change the interest rate during months in which the quarterly Inflation Report is released: Of the 31 meetings during which rates were changed, 12 took place during these months, 11 took place in the month immediately following its release, and 8 occurred in the month thereafter. Interest rate changes greater in magnitude than 25 basis points are also most likely to be made during an Inflation Report month: Only four such changes were made (all 50 basis point reductions); three of these occurred in Inflation Report months and one in the month immediately thereafter. Its publication is thus a significant event because it contains the findings of the most recent full forecasting round, the results of which are embodied in the MPC's quarterly inflation and output projections (see, e.g., Budd 1998). Further discussion of the role it plays in shaping member's policy choices is given in section 5. Group policy choices are now compared.

\section{Insiders versus Outsiders: Group Policy Choices}

The level of interest rates chosen by insiders and outsiders in MPC meetings is first examined - in particular, the suggestion that the former group are comparatively more hawkish on interest rates. ${ }^{7}$ Figure 1 plots the differences in the mean and median interest rates chosen by

\footnotetext{
${ }^{7}$ Treasury Select Committee Minutes of Evidence (Q79), Monday, June 16, 2003.
} 
Table 1. Extent to Which Internal and External Members Agree with Themselves, June 1997May 2006

\begin{tabular}{lcc}
\hline & \multicolumn{2}{c}{ No. of Meetings } \\
\cline { 2 - 3 } No of Views Held at Each Meeting & Insiders & Outsiders \\
\hline 1 & 79 & 57 \\
2 & 30 & 51 \\
3 & 0 & 1 \\
\hline
\end{tabular}

both groups. Measured in basis point units, the line labeled "Mean difference" is obtained by subtracting the mean interest rate cast by outsiders at each MPC meeting from that cast by insiders, whereas "Median difference" is calculated with the use of the median interest rate associated with each group. Post-May 1998, insiders are generally characterized by higher mean and median interest rates. ${ }^{8}$ The median difference varies by as much as 25 basis points in magnitude, as does the mean difference. A natural interpretation of this finding is that, compared with insiders, outsiders believe that relatively lower interest rates (or, one may conjecture, lower interest rate paths) are consistent with hitting target inflation. This begs the question of why outsiders systematically choose lower interest rates. In light of previous sections, perhaps the most plausible explanation is that outsiders use different information sets, have different models of the economy, or both (e.g., Wadhwani 2002). ${ }^{9}$

As shown in Table 1, insiders were in agreement with each other more so than outsiders. The overwhelming majority of MPC meetings (79) were marked by insiders sharing a single view on the immediate policy decision (i.e., voting unanimously as a group). For outsiders, although the majority of meetings were hallmarked by the presence of a single view (57 meetings), almost half were characterized by the presence of two or more (52 meetings). Such behavior is consistent with the prediction that insiders have a greater tendency to vote as a bloc (Buiter 1999; Gerlach-Kristen 2003). On average, insiders were on the winning side of a monetary policy decision $91.1 \%$ of the time, compared with $78.5 \%$ for outsiders. Put another way, insiders are far less likely to dissent than outsiders. This finding can be explained in terms of the in-built 5-4 majority insiders command over outsiders: On the basis of previous arguments, if insiders vote together because of (i) career concerns and (ii) a "Bank" consensus, their institutional majority will lead to them being on the winning side of a decision. Reaction function estimation is now turned to.

\footnotetext{
${ }^{8}$ Given that the population only contains 11 insiders and 11 outsiders, it was deemed necessary to determine whether a few accidental draws might be driving the results. All calculations (and regressions in future sections) were also performed with the simultaneous omission of Mervyn King (insider) and DeAnne Julius (outsider) from the sample. Results obtained were qualitatively similar.

${ }^{9}$ The fact that outsiders choose systematically lower interest rates than insiders also raises the question of whether the Chancellor of the Exchequer appoints outsiders on the basis of their being doves (see Dornbusch, Favero, and Giavazzi [1998, p. 25] for similar sentiments with respect to European Central Bank Governing Council appointments). An important caveat worth noting in relation to this possibility is that appointing doves does not imply appointing members who opportunistically vote to increase output with no regard for hitting the inflation target: that is, it is possible to be a dove and target inflation as a primary objective (for reasons listed above). Moreover, it makes no sense for the Chancellor to purposely appoint MPC members who would systematically undermine the monetary policy objectives of his own Government. If the Government wanted to appoint members based on their being doves, Mervyn King would arguably not have been chosen as a successor to Eddie George: Before his appointment to Governor, King cast more dissents on the side of monetary tightness than any other MPC member and no dissents on the side of monetary ease, making him the most "hawkish" member of the MPC in its first five years.
} 


\section{Model and Data}

Following Tootell (1991, 1996), Dolado, Maria-Dolores, and Naveira (2005), and, more recently, Brooks, Harris, and Spencer (2007), limited dependent variable analysis is employed to model interest rate decisions and, more specifically, the propensity of insiders and outsiders to change rates. As noted in the latter two contributions, the pattern of short-term interest rate movements associated with modern monetary policy making makes limited dependent variable analysis particularly apposite: When rates are moved, they are typically done so in fixed intervals of 25 basis point multiples. This empirical regularity also extends to members' individual votes.

Assuming that policy choices facing members have an implicit ordering makes ordered probit analysis a natural choice to model voting behavior. Write the general model as

$$
\begin{array}{lll}
y_{g t}^{*}= & \mathbf{x}_{g t}^{\prime} \beta+\varepsilon_{g t}, \\
y_{g t}=1 & \text { if } & y_{g t}^{*} \leq \gamma_{1} \\
y_{g t}=2 & \text { if } & \gamma_{1}<y_{g t}^{*} \leq \gamma_{2} \\
\vdots & & \\
y_{g t}=J-1 & \text { if } & \gamma_{J-2}<y_{g t}^{*} \leq \gamma_{J-1} \\
y_{g t}=J & \text { if } & y_{g t}^{*}>\gamma_{J-1},
\end{array}
$$

where $y_{g t}^{*}$ corresponds to member $g$ 's vote $(j=1,2, \ldots, J)$ in period $t$. $\mathbf{x}_{g t}$ is a $1 \times h$ vector containing $h$ covariates capturing the information sets of MPC members at the time each vote was cast, and $\beta$ is a $1 \times h$ vector of parameters. $\gamma_{1}, \gamma_{2}, \ldots, \gamma_{J-1}$ are the respective cutpoints. Unlike the linear probability model, marginal effects are computed by holding regressors at predetermined values, vary across choices, and sum to zero across outcomes. A member's policy response at a given meeting, $\Delta i_{g t}$, is measured in basis point units such that

$$
\begin{array}{ll}
\text { (large decrease) } y_{g t}=0 & \Leftrightarrow \Delta i_{g t}<-25, \\
\text { (small decrease) } y_{g t}=1 & \Leftrightarrow-25=\Delta i_{g t}, \\
\text { (no change) } y_{g t}=2 & \Leftrightarrow \Delta i_{g t}=0, \text { and } \\
\text { (small increase) } y_{g t}=3 & \Leftrightarrow 0<\Delta i_{g t} .
\end{array}
$$

Given a member's vote can be classified into one of four categories $(J=4)$, this implies three cut points. Figure 2 plots the distribution of members' responses according to the above ordering. ${ }^{10}$ Outsiders are less policy-inertial than insiders (56.1\% vs. $67.6 \%$ for no change), are more likely to opt for rate reductions, but are less likely to raise rates. These findings are consistent with the tendency for outsiders to vote for lower rates, as depicted in Figure 1.

\footnotetext{
${ }^{10}$ Over the sample period, the actual policy rate was never adjusted in increments other than $-50,-25,0$, and 25 basis points. This finding extends to the individual votes of all MPC members other than Willem Buiter, who cast three votes favoring a 75 basis point reduction and one favoring a 40 basis point change in the same direction. These votes are included in the $y_{g t}=0$ category, in which all remaining votes are for 50 basis point reductions. The same member also cast a single vote favoring a 50 basis point rise, which is included in the $y_{g t}=3$ category (all other votes being 25 basis point increases).
} 


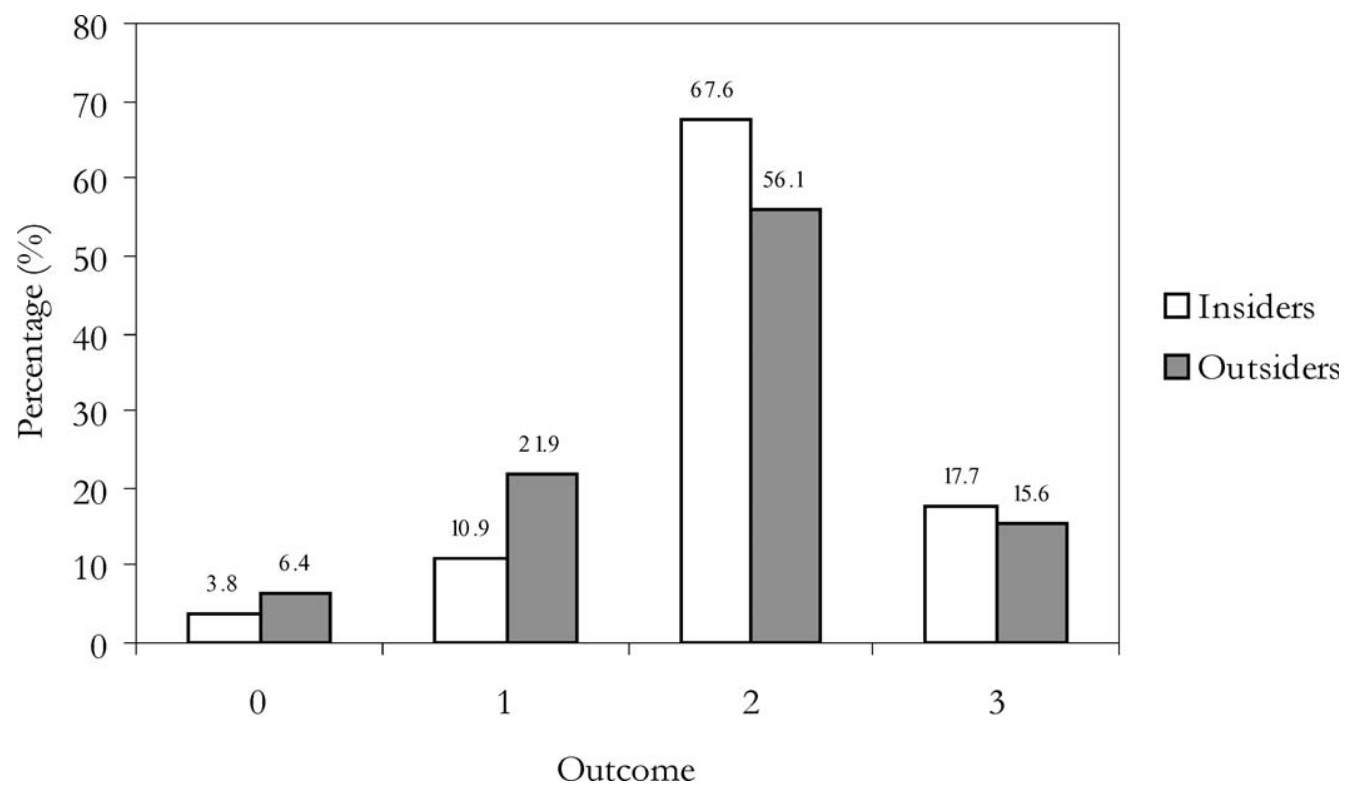

Figure 2. Distribution of members' interest rate decisions, Insiders versus Outsiders

To compare both groups, reaction functions are estimated separately for insiders and outsiders and geared to the view that the MPC changes interest rates using a simple rule analogous to Taylor (1999): Indeed, subject to maintaining price stability, a secondary objective of monetary policy is "to support the economic policy of her Majesty's Government, including its objectives for growth and employment" [Part II, Section 11 (Objectives) of the Bank of England Act 1998]. Together, the primary and secondary objectives can be interpreted as a Taylor-style monetary policy rule. However, a principal difference between the approach here and that of much of the reaction function literature is that our specification is expressed in terms of interest rate changes, as opposed to levels.

Forecast-based measures of output growth and inflation were used to construct Taylortype covariates: Specifically, the MPC's in-house modal inflation and output projections - as published in the quarterly Inflation Report-were utilized. ${ }^{11,12}$ Implicit to this approach is the view that in any month, MPC members base their policy choices on the most recently available constant (as opposed to market-based) projections. In the process of constructing our covariates, the published forecast series for inflation and output were first modified following a procedure proposed by Charles Goodhart (2005), who argues their ex post nature (i.e.,

\footnotetext{
${ }^{11}$ Although the Bank's in-house projections form a natural starting point for the choice of covariates, their quarterly frequency was initially deemed potentially problematic for the purposes of estimation - this is because the MPC makes policy decisions (and hence members cast votes) on a monthly basis. To address this issue, members' votes were also used to construct a quarterly voting series, which were then regressed on the quarterly data. Each regressand datapoint quantified the cumulative policy response of each member, defined as the difference in the interest rate chosen by each member in the second month after publication of the quarterly inflation report and the interest rate chosen by the MPC in the month immediately prior to its publication. However, as an anonymous referee has pointed out, this approach leads to a loss of voting information, making an analysis based on monthly series more desirable.

12 The Inflation Report is published in February, May, August, and November, meaning the information contained in the MPC's in-house forecasts cover three-month periods comprising either February, March, April; May, June, July; August, September, October; or November, December, January.
} 
conditioned on the interest rate prevailing after the policy decision has been taken) markedly lessens their importance in explaining the MPC's policy decisions: This is because, in practice, MPC members react to ex ante forecasts (i.e., conditioned on the interest rate set by the MPC in the previous month). With the use of published ex post modal forecasts, proxy ex ante forecasts were constructed that are potentially much closer to those on which interest rate decisions are based. ${ }^{13}$ These modified forecasts were then interpolated by a cubic spline procedure: This resulted in a monthly series characterized by a curve constrained to pass through the ex ante forecast values in Inflation Report release months, with the property that, as the next Inflation Report month approached, forecast values in the intervening months tended toward the new ex ante forecast values. An appealing interpretation of this property is that MPC members gradually revise a given set of quarterly and output inflation projections in the months after their release (i.e., because of the arrival of new economic information over time and after policy discussions with their peers and other Bank staff during the course of MPC and pre-MPC meetings), such that their values move toward those contained in the subsequent set of projections. ${ }^{14}$ The resulting series were expressed in deviation form-output growth minus potential (assumed to be $2.4 \%$ p.a.) - and the deviation of inflation from target. These series are hereafter referred to as $\mathrm{GAP}_{t}$ and $\pi_{\text {Dev }, t}$, respectively (it is assumed the forecast values in any given period are the same for all members). Finally, a forecast horizon was chosen in line with views expressed by the MPC (Monetary Policy Committee 1999) that interest rate changes take two years to maximally affect inflation and approximately one year for output. It is noted here that although additional regressions were estimated with the use of other Taylor-type covariates - constructed from (i) monthly consensus forecasts of output growth and inflation as published in Her Majesty's (HM) Treasury's Forecasts for the UK Economy, (ii) monthly estimates of GDP and inflation corresponding to current economic activity, and (iii) the MPC's own inflation and output projections-none performed as well as $\mathrm{GAP}_{t}$ and $\pi_{\text {Dev }, t}$. Our results provide compelling support for the conjecture that, in practice, not only are the MPC's inflation and output projections clearly important in capturing voting behavior, but MPC members are forward looking in their policy actions. For completeness, full results of all additional estimations, along with more complete descriptions of the variables used, are presented in the section on robustness checks in the Appendix.

Finally, in addition to the use of Taylor-type covariates to explain voting behavior, three additional variables were included in the specifications: a dummy variable capturing the effect of different MPC Chairmen ( 1 if King, 0 if George), hereafter denoted CHAIR ${ }_{t}$, and two variables capturing the effect of past interest rate decisions and policy choices. Specifically, these comprise a lagged change in the actual policy rate chosen by the MPC (hereafter denoted $\left.\Delta \tilde{i}_{t-1}\right)$; and the difference between member $g$ 's period $(t-1)$ chosen policy rate and the MPC's period $(t-1)$ policy rate (hereafter denoted Diff $\left._{t-1}\right)$. This latter term captures the extent to which a member disagrees with the winning majority of MPC members in the previous meeting.

\footnotetext{
${ }^{13}$ With respect to the choice of covariates, Besley, Meads, and Surico (2008) construct an inflation variable based on the MPC's modal projections (also conditioned on constant interest rates, as is the case here). Their output gap variable is, however, constructed with the use of confidential Bank data.

${ }^{14}$ In using the cubic spline procedure, it is noted that alternative interpolation methods were also considered by the authors, particularly those based on the utilization of a monthly indicator series (for example, the Chow-Lin (1971) procedure). However, the choice of an appropriate indicator for both output and inflation was not at all obvious. Moreover, such a procedure would not constrain the resulting interpolated estimates to equal calculated ex-ante values in Inflation Report months.
} 
Table 2. Estimation Results-Bank Forecasts ${ }^{\mathrm{a}}$

\begin{tabular}{|c|c|c|}
\hline Variables & Insiders & Outsiders \\
\hline$\pi_{\mathrm{Dev}, t}$ & $6.00^{* * *}(0.67)$ & $5.70^{* * *}(0.72)$ \\
\hline $\mathrm{GAP}_{t}$ & $0.42^{* * *}(0.12)$ & $0.18 \quad(0.12)$ \\
\hline$\Delta \tilde{i}_{t-1}$ & $1.49^{* * *}(0.42)$ & $1.78^{* * *}(0.46)$ \\
\hline $\operatorname{Diff}_{t-1}$ & $4.74^{* * *}(0.79)$ & $6.08^{* * *}(0.59)$ \\
\hline $\mathrm{CHAIR}_{t}$ & $0.18 \quad(0.14)$ & $0.005(0.16)$ \\
\hline$\gamma_{1}$ & $-2.38^{* * *}(0.18)$ & $-2.67^{* * *}(0.20)$ \\
\hline$\gamma_{2}$ & $-1.22^{* * *}(0.13)$ & $-1.01^{* * *}(0.15)$ \\
\hline$\gamma_{3}$ & $1.61^{* * *}(0.14)$ & $1.49^{* * *}(0.15)$ \\
\hline \multicolumn{3}{|c|}{ Summary statistics } \\
\hline $\mathrm{AIC}^{\mathrm{b}}$ & 714.658 & 633.848 \\
\hline $\mathrm{BIC}^{\mathrm{c}}$ & 748.627 & 665.997 \\
\hline $\log L$ & -349.329 & -308.924 \\
\hline
\end{tabular}

a Standard errors in parentheses.

b AIC, Akaike's information criterion.

${ }^{\mathrm{c}}$ BIC, Bayesian information criterion.

* Two-tailed significance at $p<0.1$.

$* *$ Two-tailed significance at $p<0.05$.

*** Two-tailed significance at $p<0.01$.

A value of $\operatorname{Diff}_{t-1}=0$ implies that a member casts an assenting vote, whereas a positive or negative value indicates a (dissenting) vote to set a relatively higher or lower rate, respectively. This yields a specification of the form

$$
y_{g t}^{*}=\beta_{0} \pi_{\mathrm{Dev}, t}+\beta_{1} \mathrm{GAP}_{t}+\beta_{2} \Delta \tilde{i}_{t-1}+\beta_{3} \operatorname{Diff}_{t-1}+\beta_{4} \mathrm{CHAIR}_{t}+\varepsilon_{g t},
$$

which explicitly accounts for the effect of past voting behavior and past changes in the official policy rate on present voting decisions. Moreover, estimates presented in the following section indicate that such variables play an important role in explaining voting behavior. ${ }^{15}$

\section{Estimation Results and Policy Response Profiles}

All estimates are reported in Table 2 (total observations [obs] $=927$; insider obs $=516$; outsider obs $=411$ ). In both specifications, coefficients on $\pi_{\mathrm{Dev}, t}$ are statistically significant across both groups of members and markedly greater than those on the output gap, which, although correctly signed, is insignificant for outsiders. ${ }^{16}$ Voting behavior does not appear to be affected by the tenure of different chairmen, as evidenced by the statistical insignificance of the $\mathrm{CHAIR}_{t}$ dummy. ${ }^{17}$ However, as mentioned previously, the effect of previous voting behavior

${ }^{15}$ We are grateful to two anonymous referees for helpful comments and suggestions with respect to the choice of covariates.

${ }^{16}$ All regressions were initially estimated with a dummy and interaction term to take into account the effect of changing the inflation target from $2.5 \%$ RPIX inflation to $2 \%$ CPI inflation. Both variables were found to be statistically insignificant and were subsequently dropped. An interpretation of this finding is that MPC members respond in the same way to equivalent-sized deviations in both inflation measures from their respective target values.

${ }^{17}$ The analysis was also extended to splitting the sample into time frames on the basis of the different committee chairs (the insider-outsider split was maintained throughout). Although some evidence suggests that members responded differently under different chairmen, it was still found that insiders and outsiders differed in their behavior in much the same way reported in the main findings. However, because of the smaller sample size (and the associated loss of degrees of freedom), some estimation problems were encountered, and it was felt that the results were not robust. 
Table 3. Marginal Effects-Bank Forecasts ${ }^{\mathrm{a}, \mathrm{b}}$

\begin{tabular}{|c|c|c|c|c|c|}
\hline \multirow{2}{*}{$\frac{\text { Variable }}{\pi_{\mathrm{Dev}, t}}$} & \multirow{2}{*}{$\begin{array}{c}\frac{y_{g t}}{0} \\
0\end{array}$} & \multicolumn{2}{|c|}{ Insiders } & \multicolumn{2}{|c|}{ Outsiders } \\
\hline & & $-0.14^{* *}$ & $(0.06)$ & $-0.06^{*}$ & $(0.04)$ \\
\hline & 1 & -1.00 & $(0.19)$ & $-1.30^{* * *}$ & $(0.24)$ \\
\hline & 2 & $0.48^{* * *}$ & $(0.30)$ & $0.61^{*}$ & $(0.35)$ \\
\hline & 3 & $0.66^{* * *}$ & $(0.14)$ & $0.75^{* * *}$ & $(0.17)$ \\
\hline \multirow[t]{4}{*}{$\mathrm{GAP}_{t}$} & 0 & $-0.01^{*}$ & $(0.01)$ & -0.002 & $(0.002)$ \\
\hline & 1 & $-0.07^{* * *}$ & $(0.03)$ & -0.04 & $(0.03)$ \\
\hline & 2 & 0.03 & $(0.03)$ & 0.02 & $(0.02)$ \\
\hline & 3 & $0.04^{* * * *}$ & $(0.01)$ & 0.02 & $(0.02)$ \\
\hline \multirow{4}{*}{$\Delta \tilde{i}_{t-1}$} & 0 & $-0.03^{* *}$ & $(0.02)$ & $-0.02^{*}$ & $(0.01)$ \\
\hline & 1 & $-0.25^{* * *}$ & $(0.08)$ & $-0.40^{* * *}$ & $(0.11)$ \\
\hline & 2 & 0.12 & $(0.08)$ & $0.19^{*}$ & $(0.11)$ \\
\hline & 3 & $0.16^{* * *}$ & $(0.06)$ & $0.23^{* * *}$ & $(0.08)$ \\
\hline \multirow[t]{4}{*}{$\operatorname{Diff}_{t-1}$} & 0 & $-0.11^{* *}$ & $(0.05)$ & $-0.07^{*}$ & $(0.04)$ \\
\hline & 1 & $-0.79^{* * *}$ & $(0.18)$ & $-1.38^{* * *}$ & $(0.22)$ \\
\hline & 2 & 0.38 & $(0.24)$ & $0.65^{*}$ & $(0.36)$ \\
\hline & 3 & $0.52^{* * * *}$ & $(0.13)$ & $0.80^{* * *}$ & $(0.19)$ \\
\hline \multirow[t]{4}{*}{$\mathrm{CHAIR}_{\mathrm{t}}{ }^{\mathrm{c}}$} & 0 & -0.003 & $(0.003)$ & -0.00006 & $(0.002)$ \\
\hline & 1 & -0.03 & $(0.02)$ & -0.001 & $(0.04)$ \\
\hline & 2 & 0.01 & $(0.01)$ & 0.0005 & $(0.02)$ \\
\hline & 3 & 0.02 & $(0.02)$ & 0.0007 & $(0.02)$ \\
\hline
\end{tabular}

${ }^{\text {a }}$ Standard errors in parentheses.

${ }^{\mathrm{b}}$ Marginal effects calculated holding all variables at 0 .

c CHAIR is evaluated as the discrete change of the Chairman dummy from 0 to 1 .

* Two-tailed significance at $p<0.1$.

** Two-tailed significance at $p<0.05$.

*** Two-tailed significance at $p<0.01$.

and past changes in the official policy rate appear to be significant determinants of voting decisions. In all estimations, parameter estimates appertaining to $\Delta \tilde{i}_{t-1}$ and Diff $\operatorname{Dir}_{t-1}$ are larger for outsiders, suggesting that the effect of past behavior and previous MPC voting decisions on current voting behavior is more pronounced for this group. Likelihood ratio tests were also conducted to test the hypothesis that all regressions should be estimated separately for insiders and outsiders. The hypothesis was overwhelmingly accepted in every case (results available on request), a result that adds to the weight of evidence in section 4 that a member's type has a significant bearing on MPC voting outcomes. However, to gauge the effect of a change in a given covariate, marginal effects (MEs) need to be calculated for all four outcomes $\left(y_{g t}=0,1\right.$, 2, 3). To make results between groups directly comparable (and to correct for differences in sample means caused by the different sample sizes associated with both groups), MEs are calculated across all specifications, holding all variables at zero, and are presented in Table 3.

For both groups of cohorts, the probability of changing the interest rate is most greatly affected by deviations of forecast inflation from target and those variables corresponding to the effect of past policy actions and voting behavior. Reassuringly, the MEs for increases and decreases in inflation are correctly signed and, in all cases, statistically significant. This accords with the view that a rise (fall) in forecast inflation above target level is likely to induce a tightening (loosening) of policy. Although $\mathrm{GAP}_{t}$ is only significant for insiders, it is nevertheless correctly signed. The effects of a change in $\mathrm{GAP}_{t}$ are small, a finding that reflects the small parameter estimates corresponding to this variable. 
Policy responses given no dange in the period $t-1$ policy rate and Diff $_{f-1}=0$

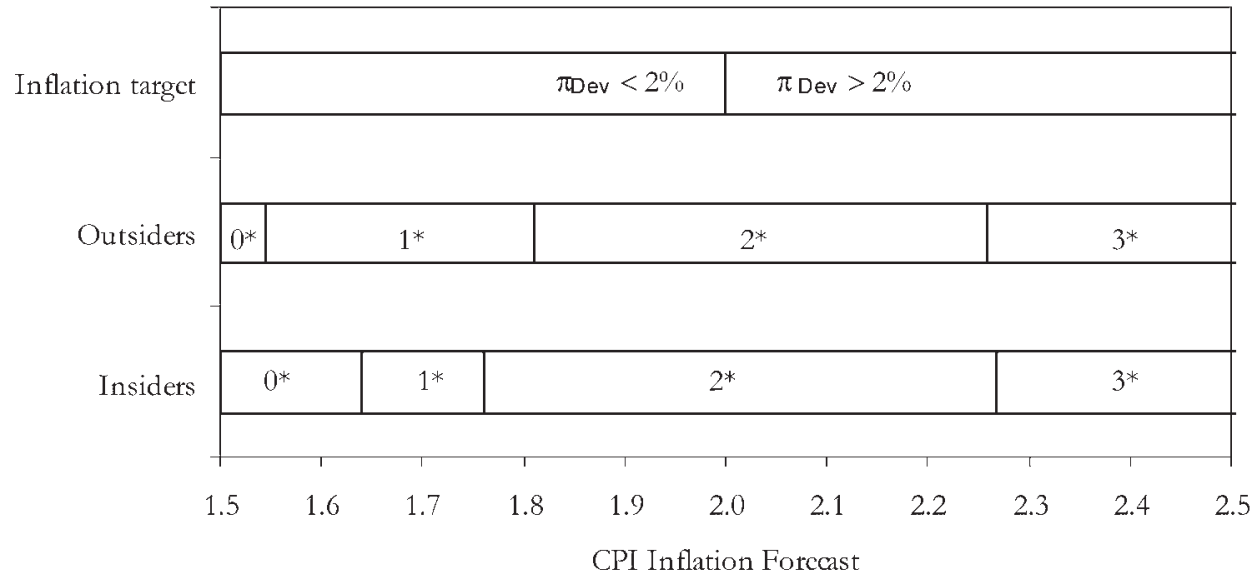

Policy responses given a 0.25 decrease in the period $t-1$ policy rate and $\operatorname{Diff}_{f-1}=-0.25$

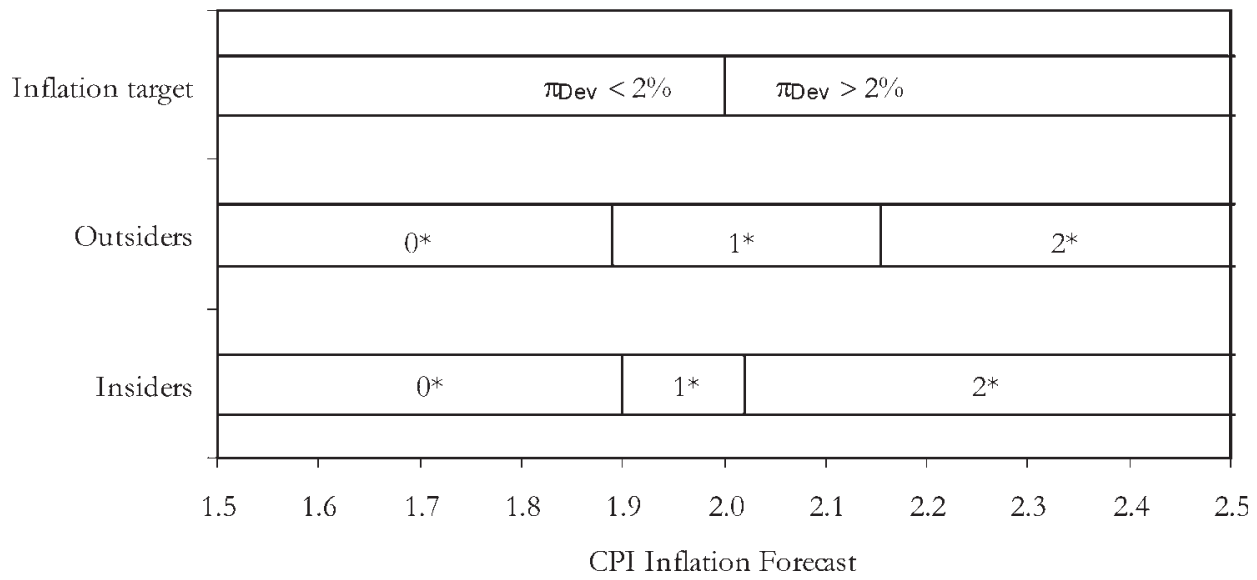

Figure 3. Policy response profiles for Insiders and Outsiders under different policy scenarios

Yet only calculating the MEs is in some respects not entirely satisfactory for the purposes of this paper because their values are typically unique to the predetermined values at which covariates are held; put another way, the calculated change in probability associated with a given voting outcome is at best only accurate for very (ideally infinitesimally) small changes in a covariate.

Therefore, whilst the convention of reporting MEs is adopted, understanding the behavior of each group is enhanced by the inclusion of their policy response profiles. Displayed in Figure 3, these show the course of action most likely to be adopted by each group across 
different CPI forecast values on the basis of the ordering identified in Equation $3 ;{ }^{18}$ here, the most likely voting response corresponds to the range of CPI values over which the probability of each outcome occurring $(j=0,1,2,3)$ is highest.

For the four outcome case, and in keeping with Equation 3, policy responses are denoted as follows: $0^{*}$ (large decrease), $1^{*}$ (small decrease), $2^{*}$ (no change), and $3^{*}$ (small increase). ${ }^{19}$ Figure 3 contains two charts, in each of which the upper horizontal bar identifies the $2 \%$ inflation target and the two lower bars depict the most probable policy responses for outsiders and insiders, respectively. With respect to both charts, it is notable that members of each group differ in their propensity to change interest rates, supporting the view that insiders and outsiders differ in their voting behavior. Moreover, the range of inflation forecast values over which members" policy responses are distributed is within the "acceptable" range of inflation outcomes stipulated in the MPC's remit (1-3\% for CPI inflation), values outside of which trigger an open letter to the Chancellor. Indeed, for both groups of cohorts, policy responses are distributed across a relatively small range of CPI forecast values; and, although the size of output deviations predicted to trigger rate increases and decreases (not shown here) typically lie well outside the range of in-sample values (minimum value $=-1.565$; maximum value $=0.98$ ), this is not the case for policy responses appertaining to $\pi_{\text {Dev, } t}$ (minimum value $=-0.29$, maximum value $=0.27$ ).

The top chart in Figure 3 illustrates voting responses across different CPI forecast values, assuming that the actual policy rate chosen by the MPC in the previous meeting was left unchanged $\left(\Delta \tilde{i}_{t-1}=0\right)$ and, furthermore, that an assenting vote was cast $\left(\operatorname{Diff}_{t-1}=0\right)$. Here, outsiders are generally seen to require smaller deviations from target inflation in either direction to trigger an increase or decrease in the interest rate. In this sense, outsiders react more aggressively with respect to deviations of (forecast) CPI inflation in their pursuit of target inflation. This also reflects the empirical regularity that insiders are more likely to vote for no change in the interest rate.

The estimated coefficients on $\Delta \tilde{i}_{t-1}$ and Diff $t_{t-1}$ also imply that past policy rate changes and dissents have a more pronounced effect on the tendency for outsiders to vote for a rate change. This finding reflects the larger coefficient sizes for these variables associated with this group of cohorts. Indeed, when the effects of a previous dissent or policy rate change are examined in isolation (e.g., by setting Diff $f_{t-1}=-0.25$ and $\Delta \tilde{i}_{t-1}=0$ or $\operatorname{Diff}_{t-1}=0$ and $\left.\Delta \tilde{i}_{t-1}=-0.25\right)$, important conclusions can be drawn. First, a dissent on the side of monetary ease (tightness) is most likely to lead outsiders to vote for a rate reduction (increase) in the following period. Second, a reduction (increase) in the period $t-1$ policy rate is most likely to lead outsiders to vote for a rate reduction (increase) next period. The lower chart in Figure 3

\footnotetext{
${ }^{18}$ As estimates suggest, members prescribe the same policy response to equivalent-sized deviations in forecasts of CPI and RPIX inflation from their respective target measures; only charts corresponding to CPI inflation (the current target measure) are presented. Because the coefficients associated with the output gap are small — and in the case of outsiders, insignificant - corresponding policy response profiles are not presented here. Such profiles show that deviations in forecast output from potential lying well outside the sample range are required to trigger a vote to change the interest rate.

${ }^{19}$ In all profiles, responses to forecast inflation are calculated by holding the values of all other covariates at predetermined levels $\left(\mathrm{CHAIR} t\right.$ and $\mathrm{GAP}_{\mathrm{t}}=0$, whereas other variables are set as outlined above) and numerically recovering the range of forecast inflation values over which each outcome is most likely to occur. Because these recovered values will be in deviation form, target inflation is then added to give the range of forecast values (shown on the horizontal axis), to which each group is assumed to respond.
} 
combines these effects, depicting the most likely policy responses after a 25-basis point decrease in the period $t-1$ policy rate $\left(\Delta \tilde{i}_{t-1}=-0.25\right)$ coupled with a dissenting vote cast on the side of monetary ease ( Diff $_{t-1}=-0.25$ ). Clearly, outsiders emerge as being far more likely to vote for a rate reduction across the range of CPI forecast values shown.

\section{Discussion}

The analysis confirms that the institutional status of Bank of England MPC members has a significant bearing on their policy choices. Compared with outsiders, insiders are more likely to choose higher interest rates, vote as a bloc, and feature on the winning side of decisions. Ordered probit estimates indicate that each group is characterized by different reaction functions: Outsiders are shown to respond more aggressively to positive and negative deviations in inflation from target; additionally, the role of past voting behavior and policy decisions is different across groups. Many of these results are in line with earlier stated priors.

One question not yet touched on is whether such voting outcomes are desirable. As stated in the Introduction, the existence of outsiders is justified on the grounds that policy meetingsand by implication policy decisions - benefit from the presence of both Bank and non-Bank views. In practice, outsiders bring alternative views to the table: Evidence of this is readily found in the Minutes of MPC meetings and other written sources (i.e., Goodhart, 2001; Wadhwani 2002). Frequently, though, insiders are seen to dominate MPC decisions. As has been argued, this stems from their tendency to vote together as a group, coupled with their 5-4 institutional majority over outsiders. On this evidence, the structure of the MPC is somewhat biased toward the policy choices of insiders. But is this necessarily a problem for the MPC? The answer is potentially, yes.

The earlier notion that insiders vote together because of an organizational consensus is in many respects equivalent to saying that insiders bring the same view to MPC discussions. This runs contrary to one of the main perceived benefits of group decision making: that committees make better decisions than individuals because of the diverse views brought to the group by different members. ${ }^{20}$ Attributing insider bloc voting to career concerns is equally problematic: Even if insiders share different views, they can be disincentivized from revealing or voting in accordance with them. The benefits associated with a heterogeneous committee are hence reduced.

The prospect of group consensus formation has led Willem Buiter (1999) to advocate that the majority of Bank of England MPC members should not emanate from a single organization such as the Bank. On this analysis, the design of the MPC might be viewed as fundamentally unsound. One solution to this perceived problem is to reduce the number of insiders on the committee, as proposed by Sibert (2006), who suggests decreasing their number from five to three. This could in principle engender policy decisions that better reflect the diversity of views outsiders bring to deliberations: By no longer commanding an institutional majority, insiders

\footnotetext{
${ }^{20}$ In addition to this perceived benefit, Blinder (2007, p. 121) argues that MPCs benefit from a "larger and more diverse knowledge base, different decision heuristics, and a built-in system of checks and balances."
} 
would be unable to dominate decisions, as is current practice. ${ }^{21}$ However, the prospect of such an innovation raises a well-founded (and obvious) objection: Despite its current design, the MPC still met its policy objectives in its first nine years, so why "fix" the MPC if it is not "broken"? However, if a central objective was to design a framework in which interest rate decisions were not subject to a single group dominating policy decisions, the present framework of the MPC is flawed, and the perceived benefits of committee decision making are not being fully exploited.

\section{Appendix: Robustness Checks}

Regressions were performed with the use of a number of alternative monthly inflation and output series; however, on the basis of Akaike's information criterion, the Bayesian information criterion, and pseudo- $R^{2}$ goodness of fit measures, none performed as well as $\mathrm{GAP}_{t}$ and $\pi_{\text {Dev }, t}$. Monthly series constructed from (i) current monthly estimates of GDP and inflation, (ii) monthly consensus forecasts of output growth and inflation as published in HM Treasury's Forecasts for the UK Economy, and (iii) the underlying output and inflation projections used in the construction of $\mathrm{GAP}_{t}^{*}$ and $\pi_{\mathrm{Dev}, t}$ were considered. Table 4 reports these additional findings, wherein all output gap and inflation deviation measures are denoted GAP* and $\pi_{\mathrm{Dev}, t}$. Appealing to goodness of fit criteria and summary statistics, regressions that use Taylor-type variables constructed from economic forecasts performed most favorably, with those based on official Bank forecasts performing best. ${ }^{22}$

For (i), monthly GDP estimates were constructed from (current, nonforecast) GDP data according to the interpolation procedure of Chow and Lin (1971), in which the monthly index of industrial production was adopted as the indicator variable. The resulting series was then smoothed with the Hodrick-Prescott filter to proxy for potential output, and an output gap measure was constructed by calculating the differences in the monthly annual growth rates corresponding to each series. For the inflation term, deviations in the contemporaneous rate of inflation minus the corresponding target rate were used. Both the inflation and output variables were lagged (by one month) to take into account the data available to the MPC at the time of a decision. According to the reported estimates, inflation has no role (statistically insignificant), although the output gap is significant and correctly signed. Finally, the lagged variables in both specifications are highly significant for both groups of members, a result that holds irrespective of the choice of Taylor-type covariates. Of particular interest is the finding that in all but one

\footnotetext{
${ }^{21}$ The finding that outsiders have a greater propensity for changing rates is of some interest in relation to this conjecture. Would, for example, an outsider-dominated MPC set policy characterized by more frequent rate changes? This may not necessarily be the case. Whilst it is plausible to infer that under such a structure rates would be lower, outsiders' greater propensity to vote for change may merely reflect their attempts to put the economy on a lower interest rate path, which if realized might exhibit no less policy inertia than the (higher) path observed under an insider-dominated committee. Further, reducing the number of insiders would render them less able to exploit their 'bloc vote', leaving them more vulnerable to being on the losing side of decisions. This may ultimately manifest itself in insiders voting to change rates with a higher frequency than outsiders (i.e., to put the economy back onto their 'preferred' higher interest rate path).

22 Clarida, Gali, and Gertler (2000) assert that forecasts “. . . allow the central bank to consider a broad array of information (beyond lagged information and output) to form beliefs about the future condition of the economy, a feature which ... [is] highly realistic" (p. 151).
} 
Table 4. Additional Estimation Results ${ }^{\mathrm{a}}$

\begin{tabular}{|c|c|c|c|c|c|c|}
\hline \multirow[b]{2}{*}{$\underline{\text { Variables }}$} & \multicolumn{3}{|c|}{ Current Activity } & \multicolumn{3}{|c|}{ Consensus Forecasts } \\
\hline & \multicolumn{2}{|c|}{ Insiders } & Outsiders & \multicolumn{2}{|c|}{ Insiders } & Outsiders \\
\hline$\pi_{\mathrm{Dev}, t}$ & -0.19 & $(0.15)$ & $-0.14 \quad(0.16)$ & 0.39 & $(0.27)$ & $0.48^{*} \quad(0.29)$ \\
\hline $\mathrm{GAP}_{t}^{*}$ & $0.22^{* *}$ & $(0.09)$ & $0.29^{* * *}(0.10)$ & $0.92^{* * *}$ & $(0.13)$ & $0.76^{* * *}(0.15)$ \\
\hline$\Delta \tilde{i}_{t-1}$ & $3.18^{* * *}$ & $(0.38)$ & $3.13^{* * *}(0.42)$ & $1.81^{* * *}$ & $(0.44)$ & $2.11^{* * *}(0.48)$ \\
\hline $\operatorname{Diff}_{t-1}$ & $4.97^{* * *}$ & $(0.76)$ & $6.21^{* * *}(0.57)$ & $4.45^{* * *}$ & $(0.77)$ & $5.94^{* * *}(0.58)$ \\
\hline $\mathrm{CHAIR}_{t}$ & $-0.32^{* * *}$ & $(0.12)$ & $-0.34^{* *} \quad(0.13)$ & $-0.23^{*}$ & $(0.12)$ & -0.27 \\
\hline$\gamma_{1}$ & $-2.36^{* * *}$ & $(0.16)$ & $-2.67^{* * *}(0.18)$ & $-2.65^{* * *}$ & $(0.18)$ & $-2.85^{* * *}(0.20)$ \\
\hline$\gamma_{2}$ & $-1.42^{* * *}$ & $(0.12)$ & $-1.25^{* * *}(0.13)$ & $-1.61^{* * *}$ & $(0.13)$ & $-1.35^{* * *}(0.14)$ \\
\hline$\gamma_{3}$ & $0.99^{* * *}$ & $(0.11)$ & $0.98^{* * *}(0.13)$ & $0.93^{* * *}$ & $(0.11)$ & $0.91^{* * *}(0.13)$ \\
\hline \multicolumn{7}{|c|}{ Summary statistics } \\
\hline $\mathrm{AIC}^{\mathrm{b}}$ & 836.143 & & 710.940 & 794.725 & & 694.329 \\
\hline $\mathrm{BIC}^{\mathrm{c}}$ & 870.174 & & 743.128 & 828.755 & & 726.517 \\
\hline $\log L$ & -410.071 & & -347.470 & -389.362 & & -339.165 \\
\hline
\end{tabular}

a Standard errors in parentheses.

b AIC, Akaike's information criterion.

${ }^{\mathrm{c}}$ BIC, Bayesian information criterion.

* Two-tailed significance at $p<0.1$.

** Two-tailed significance at $p<0.05$.

$* * *$ Two-tailed significance at $p<0.01$

set of estimates (Current activity), the coefficients corresponding to $\Delta \tilde{i}_{t-1}$ and Diff ${ }_{t-1}$ are greater for outsiders.

In the case of (ii), for each month the average of 12-month-ahead GDP (growth) consensus forecasts minus potential (assumed to be a growth rate of $2.4 \%$ p.a.) and the difference between 12-month-ahead consensus inflation forecasts and the target rate were used. ${ }^{23}$ Again, these variables were lagged (in this case by one month) to take into account the forecast data available to the MPC at the time of a decision. Forecast variables for GDP growth and inflation were obtained from HM Treasury's Forecasts for the UK Economy. Published monthly, this is a compendium of forecasts produced by city and independent forecasters. Here, it is noted that although the Bank of England's quarterly inflation and GDP projections are purportedly central to interest rate decisions, the Inflation Report and Minutes of MPC Meetings also make reference to consensus forecasts. For estimation purposes, the average of new inflation and output forecasts reported in a given month were used (over the course of the sample, forecasts from more than 50 city institutions and 20 independent forecasters were used). As noted, although these regressions out-performed those based on contemporaneous variables, they did not perform as well as those based on official forecasts. Furthermore, although output (correctly signed) has a role, deviations from target inflation are insignificant. Like the regressions based on current economic conditions, the role of the Chairman is found to be significant, although only marginally. This is not the case for estimates based on the MPC's inflation and output projections, which are now turned to.

With respect to (iii), three results are notable. First, estimation results support the finding in Goodhart (2005) that MPC decisions are better modeled by ex ante and not ex post forecasts (estimates not presented here because of space constraints). Second, the preferred series

\footnotetext{
${ }^{23}$ Full details of how the 12-month-ahead forecast variables were constructed are available from the authors on request.
} 
Table 4. Extended.

\begin{tabular}{|c|c|c|c|}
\hline \multicolumn{2}{|c|}{ Bank Forecasts $_{\mathrm{G}}$} & \multicolumn{2}{|c|}{ Bank Forecasts $_{M}$} \\
\hline Insiders & Outsiders & Insiders & Outsiders \\
\hline $5.14^{* * *}(0.65)$ & $2.83^{* * *}(0.64)$ & $2.37^{* * *}(0.41)$ & $1.81^{* * *}(0.44)$ \\
\hline $0.50^{* * *}(0.12)$ & $0.22^{*} \quad(0.12)$ & $0.55^{* * *}(0.12)$ & $0.34^{* * *}(0.12)$ \\
\hline $1.19^{* * *}(0.43)$ & $2.28^{* * *}(0.46)$ & $1.63^{* * *}(0.43)$ & $2.14^{* * *}(0.47)$ \\
\hline $4.16^{* * *}(0.79)$ & $5.97^{* * *}(0.59)$ & $4.42^{* * *}(0.76)$ & $6.24^{* * *}(0.58)$ \\
\hline $0.16 \quad(0.14)$ & $-0.10 \quad(0.15)$ & $0.001 \quad(0.14)$ & $-0.13 \quad(0.15)$ \\
\hline$-2.31^{* * *}(0.17)$ & $-2.56^{* * *}(0.19)$ & $-2.40^{* * *}(0.17)$ & $-2.63^{* * *}(0.19)$ \\
\hline$-1.19^{* * *}(0.13)$ & $-1.02^{* * *}(0.14)$ & $-1.29^{* * *}(0.13)$ & $-1.07^{* * *}(0.14)$ \\
\hline $1.55^{* * *}(0.13)$ & $1.23^{* * *}(0.14)$ & $1.30^{* * *}(0.12)$ & $1.17^{* * *}(0.14)$ \\
\hline 737.376 & 687.997 & 767.851 & 686.275 \\
\hline 771.345 & 720.146 & 801.820 & 718.424 \\
\hline-360.688 & -335.999 & -375.925 & -335.137 \\
\hline
\end{tabular}

modified à la Goodhart (2005) and subsequently interpolated with the cubic spline procedure outperforms regressions that assume MPC members only respond to the most recent quarterly ex ante forecast in any given month. For example, if the ex ante modal inflation forecast is calculated as $1.9 \%$ for the February Inflation Report, this is the value members are assumed to base their voting decisions on in the following two months, until the release of the new forecast in May, and so on. It is an approach that amounts to saying that in the two months following the release of the MPC's quarterly inflation and output projections, members do not base their voting decisions on any new information. Regressions with variables constructed according to this assumption are labeled Bank Forecasts ${ }_{\mathrm{G}}$, wherein, as in the preferred model, output gaps are constructed by assuming that the level of potential output is $2.4 \%$ p.a. Third, as an alternative approach to cubic spline interpolation, Goodhart's (2005) method was further extended to construct a "monthly ex ante" series whereby for any given month (as opposed to only the month in which the new quarterly forecast is published), the most recent set of in-house forecasts were conditioned on the interest rate set the previous month (Bank Forecasts $\mathrm{M}_{\mathrm{M}}$ ). This implies that if, for example, official rates are adjusted in the second and third months after the release of the Inflation Report, the original ex ante forecasts are further adjusted to reflect these changes. Although this approach is intuitively appealing, summary statistics indicated it explained MPC voting behavior less satisfactorily than when Bank Forecasts ${ }_{\mathrm{G}}$ were used. In many respects, this finding might be seen as reinforcing Budd's (1998, p. 1790) assertion that revisions to the MPC's forecasts in non-Inflation Report months are no substitute for the "complete reassessment of all the evidence that is involved in a full forecasting round." However, the interpolated forecasts in turn out-performed Bank Forecasts ${ }_{\mathrm{G}}$, providing a more mixed message. Yet ultimately, when considered as a whole, the estimation results presented in this paper highlight the clear importance of the Bank's in-house forecasts as determinants of voting behavior.

\section{References}

Bank of England. 1998. Bank of England Act 1998. Accessed 15 June 2009. Available http://www.bankofengland.co.uk/ about/legislation/1998act.pdf. 
Besley, Timothy, Neil Meads, and Paolo Surico. 2008. Insiders versus outsiders in monetary policymaking. American Economic Review 98:218-23.

Bhattacharjee, Arnab, and Sean Holly. 2004. Inflation targeting, committee decision making and uncertainty: The case of the Bank of England's MPC. Cambridge Working Papers in Economics No. 0503, University of Cambridge, Cambridge, UK.

Blinder, Alan. 2007. Monetary policy by committee: Why and how? European Journal of Political Economy 23:106-23.

Brooks, Robert, Mark Harris, and Christopher Spencer. 2007. An inflated ordered probit model of monetary policy: Evidence from MPC voting data. MPRA Paper 8509, University Library of Munich, Germany.

Budd, Alan. 1998. The role and operations of the Bank of England Monetary Policy Committee. Economic Journal 108:1783-94.

Buiter, Willem. 1999. Answers to the questionnaire "Bank of England Commission; Issues for consideration." Accessed 23 October 2008. Available http://www.nber.org/ wbuiter/question.pdf.

Chevapatrakul, Thanaset, Paul Mizen, and Tae-Hwan Kim. 2003. Predicting changes in the interest rate: The performance of Taylor Rules versus alternatives for the United Kingdom. Royal Economic Society Annual Conference 2003 No. 122, Royal Economic Society, St. Andrews, UK.

Chow, Gregory C., and Lin An-loh. 1971. Best linear unbiased interpolation, distribution, and extrapolation of time series by related series. Review of Economics and Statistics 53:372-5.

Clarida, Richard, Jordi Gali, and Mark Gertler. 2000. Monetary policy rules and macroeconomic stability: Evidence and some theory. The Quarterly Journal of Economics 115(1):147-80.

Dolado, Juan, Ramon Maria-Dolores, and Manuel Naveira. 2005. Are monetary policy reaction functions asymmetric? The role of non-linearity in the Phillips curve. European Economic Review 49:485-503.

Dornbusch, Rudi, Carlo Favero, and Francesco Giavazzi. 1998. Immediate challenges for the European Central Bank. Economic Policy 26:15-52.

Edmonds, Timothy. 1999. The Monetary Policy Committee: Theory and performance. House of Commons Research Paper 99/17.

Gascoigne, Jamie, and Paul Turner. 2004. Asymmetries in Bank of England monetary policy. Applied Economics Letters 11:615-18.

Gerlach-Kristen, Petra. 2003. Insiders and outsiders at the Bank of England. Central Banking 14:96-102.

Gerlach-Kristen, Petra. 2004. Is the MPC's voting record informative about future UK monetary policy? Scandinavian Journal of Economics 106:299-313.

Gerlach-Kristen, Petra. 2008. The role of the Chairman in setting monetary policy: Individualistic vs autocratically collegial MPCs. International Journal of Central Banking 4:119-43.

Goodhart, Charles A. E. 2001. The inflation forecast. National Institute Economic Review 175:59-66.

Goodhart, Charles A. E. 2005. The Monetary Policy Committee's reaction function: An exercise in estimation. Topics in Macroeconomics 5(1):Article 18.

Harris, Mark, and Christopher Spencer. 2008. Decade of dissent: Explaining the dissent voting behavior of Bank of England MPC members. MPRA Paper 9100, University Library of Munich, Germany.

Havrilesky, Thomas, and Robert Schweitzer. 1990. A theory of FOMC dissent voting with evidence from the time series. In The political economy of American monetary policy, edited by Thomas Mayer. Cambridge: Cambridge University Press, pp. 197-210.

House of Lords. 30 July 1999. Monetary Policy Committee of the Bank of England - Report. HL 96, Chapter 2, Para 2.32.

Monetary Policy Committee. 1999. The transmission mechanism of monetary policy. Accessed 10 October 2008. Available http://www.bankofengland.co.uk/publications/other/monetary/montrans.pdf.

Sibert, Anne. 2006. Deconstructing the Bank of England Act 1998. Mimeo, Birkbeck College, University of London

Taylor, John B. (ed.). 1999. Monetary policy rules. Chicago: University of Chicago Press.

Tootell, Geoffrey. 1991. Are district presidents more conservative than board governors? New England Economic Review. 1991(September/October):3-12.

Tootell, Geoffrey. 1996. Appointment procedures and FOMC voting behavior. Southern Economic Journal 63:191-204.

Wadhwani, Sushil B. 2002. The MPC: Some further challenges. Speech delivered at the National Institute of Economic and Social Research Governors' Seminar, London, 16 May 2002.

Wallis, Kenneth. 2002. Chi-squared tests of interval and density forecasts, and the Bank of England's fan charts. Royal Economic Society Annual Conference 2002 No. 181, Royal Economic Society. 